\title{
Alloying of Materials and Energy Barriers of Photoelectric Thermal Cells
}

\author{
M. S. Saidov \\ Physical Technical Institute, Physics of the Sun Scientific Association, Academy of Sciences of the Republic of Uzbekistan, \\ Tashkent, Uzbekistan \\ e-mail:sh_usmonov@rambler.ru \\ Received April 10, 2014
}

\begin{abstract}
The possibility for designing highly effective photoelectric thermal cells on the basis of heavily alloyed narrow-zone semiconductors with forbidden bandwidths of $0.3-0.4 \mathrm{eV}$ is discussed.
\end{abstract}

DOI: $10.3103 / \mathrm{S} 0003701 \mathrm{X} 14040148$

Pilot studies aimed at designing highly effective affordable semiconductor solar-to-electric energy converters are a long-term topical task of semiconductor physics. In $[1,2]$ the idea of producing photoelectric thermal cells with narrow-zone layers was proposed, in which photogeneration and thermal generation of electron-hole $(\mathrm{e}-\mathrm{h})$ couples would occur, as well as approximate evaluation of its ultimate effectiveness, depending on the height of the $p-n$ transition energy barrier.

This short paper considers the $p-n$ transition energy barrier in photoelectric thermal cells relative to the temperature.

As an example, we will try to define the temperature relationship of the energy barrier in commercial $\mathrm{Si}$ photoelectric cells. Let the effectiveness of Si solar power cells (SPC) at room temperature be $20 \%$, the concentration of free $n$ layer equilibrium electrons $\sim 10^{10} \mathrm{~cm}^{-3}$, and the concentration of $p$ layer equilibrium holes $\sim 10^{6} \mathrm{~cm}^{-3}$, whereas the generated $\mathrm{e}-\mathrm{h}$ couples are divided by the $p-n$ transition field without recombination. In the $p$ layer $E_{F}-E_{V} \approx 0.2 \mathrm{eV}$, and in the $n$ layer $E_{C}-E_{F} \approx 0.05 \mathrm{eV}$ : that is the reason that the threshold height of the $p-n$ transition energy barrier $\sim 0.8 \mathrm{eV}$ and the idle run voltage $V_{\text {ir }} \approx 0.65 \mathrm{~V}$, i.e., $20 \%$ less than the former index. At $350^{\circ} \mathrm{C} E_{F}-E_{V} \approx 0.45 \mathrm{eV}$ and $E_{C}-E_{F} \approx 0.2 \mathrm{eV}$; therefore, the barrier height will be $\sim 0.35 \mathrm{eV}$ and $V_{\text {ir }} \approx 0.2 \mathrm{~V}$.

At $350^{\circ} \mathrm{C}$ the concentration of thermally generated $\mathrm{e}-\mathrm{h}$ couples in an Si SPC will be $\sim 10^{15} \mathrm{~cm}^{-3}$. Since the concentration of $\mathrm{e}-\mathrm{h}$ couples generated in an Si SPC insolated by solar rays of $0.1 \mathrm{~W} / \mathrm{cm}^{2}$ is $\sim 3 \times 10^{14} \mathrm{~cm}^{-3}$, the short-circuit current $\left(I_{\text {sct }}\right)$ will become seven times stronger, which will improve the performance of the SPC by $24 \%$. However, this figure is never reached in experimental practice, which is seemingly caused by the high heat losses.

According to the above, it is impossible to design effective photoelectric thermal cells based on broadzone semiconductor materials.
Let us consider the possibility of adjusting the height of the $p-n$ transition barrier and effectiveness of photoelectric thermal cells in narrow-zone semiconductors. If a semiconductor photoelectric thermal cell with forbidden bandwidth $\left(E_{g}\right)-E_{g}=0.4 \mathrm{eV}$, selective covering on the front surface and thermal insulation on the back surface absorbs all the solar radiation of $0.1 \mathrm{~W} / \mathrm{cm}^{2}$, then it can heat up to $70-80^{\circ} \mathrm{C}$ or even higher via the excess energy produced by photogenerated electrons. The concentration of proper carriers at this temperature will therefore be $\sim 5 \times 10^{15} \mathrm{~cm}^{-3}$. Thus the barrier will virtually disappear at $p$ and $n$ layer alloying at $10^{16} \mathrm{~cm}^{-3}$. If both layers are alloyed to $10^{19} \mathrm{~cm}^{-3}$ the barrier will be $\sim 0.2 \mathrm{eV}$ in height, which will be two time lower than $E_{g}$. If one layer is alloyed to $10^{19} \mathrm{~cm}^{-3}$ the barrier will be $0.1 \mathrm{eV}$ in height, which will be seven times lower than $q V_{\text {ir }}$ of a Si SPC and the concentration of heat carriers of $5 \times 10^{15} \mathrm{~cm}^{-3}$ will be 12 times higher than for an SI SPC; this is the reason that the ultimate performance factor will be $\sim 40 \%$ and even $50 \%$ if both sides are alloyed to $10^{19} \mathrm{~cm}^{-3}$.

According to the above, studies of photovoltaic processes in $p-n$ transitions of narrow-zone semiconductors are of definite interest and can serve as the basis for designing highly effective photoelectric thermal elements.

\section{REFERENCES}

1. Saidov, M.S., Appl. Solar Eng., 2012, vol. 48, no. 1, p. 1.

2. Saidov, M.S., Development trends for high efficient semiconductor solar cells, Mezhd. Konf. "Fundamental'nye i prikladnye voprosy fiziki", posvyashchennaya 70-letiyu Fiziko-tekhnicheskogo instituta NPO "FizikaSolntse" AN RUz. (Proc. Int. Conf. "Fundamental and Applied Problems in Physics" Dedicated to 70th Anniversary of Institute of Materials Science, NPO "Physics-Sun" Named after Academician S.A. Azimov), Tashkent, Nov. 14-15, 2013, pp. 230-232.

Translated by S. Kuznetsov 